\title{
The Development and Psychometric Testing of a Substance Use Wellness Tool
}

\author{
Shu-Ping Chen \\ University of Alberta \\ Heather Stuart and Terry Krupa \\ Queen's University \\ Keith Dobson \\ University of Calgary \\ Sherry Stewart \\ Dalhousie University
}

\begin{abstract}
This paper describes the development and psychometric testing of the Substance Use Wellness Tool, created to help raise awareness about alcohol and other substance misuse among university undergraduates. The tool is a self- and peer-reflection guide that students can use to monitor and alter their patterns of substance use. Exploratory and confirmatory factor analysis showed that the tool was unidimensional and that all 13 assessed domains were important. Cronbach's alpha indicated the tool was highly reliable. Construct (convergent) validity for alcohol use with the 10-item AUDIT was also good, with strong correlations overall and within subgroups defined by gender, year of study, and university site.
\end{abstract}

Keywords: substance misuse; prevention; awareness

Shu-Ping Chen, Department of Occupational Therapy, University of Alberta, Edmonton, Alberta; Heather Stuart, Department of Public Health Sciences, Queen's University, Kingston, Ontario; Terry Krupa, School of Rehabilitation Therapy, Queen's University, Kingston, Ontario; Keith Dobson, Department of Psychology, University of Calgary, Calgary, Alberta; Sherry Stewart, Department of Psychiatry, Dalhousie University, Halifax, Nova Scotia.

This research was supported in part of the Caring Campus project which was funded by Movember Canada.

Correspondence concerning this article should be addressed to Shu-Ping Chen, Assistant Professor, Department of Occupational Therapy, Faculty of Rehabilitation Medicine, University of Alberta, 2-30 Corbett Hall, Edmonton, AB, T6G, 2G4. Phone: 780-4923905; Email: shuping2@ualberta.ca

The Caring Campus Toolkit is an integral part of the Caring Campus Project. The Toolkit can be accessed at https://doi.org/10.7870/ cjcmh-2018-018 


\section{RÉSUMÉ}

Le présent article décrit l'élaboration et l'évaluation psychométrique de l'Outil de bien-être lié à l'utilisation de substances créé pour aider à sensibiliser les étudiants du premier cycle universitaire à la consommation abusive d'alcool et d'autres substances. L'outil est un guide d'autoréflexion et de réflexion par les pairs que les élèves peuvent utiliser pour surveiller et modifier leurs habitudes de consommation d'alcool et d'autres drogues. L'analyse factorielle à caractère exploratoire et confirmatoire a permis de démontrer l'aspect unidimensionnel de l'outil et l'importance particulière de chacun des 13 domaines évalués. Le coefficient alpha de Cronbach a révélé que l'outil en était un très fiable. La validité conceptuelle (convergente) de la consommation d'alcool avec l'audit en 10 points s'est également avérée satisfaisante avec des niveaux de corrélation relativement élevés dans l'ensemble et au sein des sous-groupes définis selon le genre, l'année d'étude et le site universitaire.

Mots clés : usage abusif de substances, prévention, sensibilisation

\section{INTRODUCTION AND PURPOSE}

There has been increasing awareness of the need to address substance use among post-secondary students, and in particular alcohol misuse. Experience to date suggests that, despite the best efforts of university officials, researchers, health educators, and health professionals, the promotion of safe drinking and harm reduction practices among post-secondary populations has not gone well. Indeed, post-secondary students continue to stand out as having a relatively high level of binge drinking over the course of years (Johnston, O'Malley, Bachman, Schulenberg, \& Miech, 2016). Novel approaches are needed if post-secondary students are going to understand and change problematic drinking patterns (Misch, 2010).

Substance misuse among post-secondary students has implications for the physical and mental health of post-secondary students and is associated with a broad range of negative social, academic, and legal consequences (Das, Salam, Arshad, Finkelstein, \& Bhutta, 2016). There is considerable evidence that the majority of change in substance use comes from people's own self-change efforts (Sobell \& Sobell, 2005), and one thing that is useful in self-change efforts is accurate information about how risky one's behaviour is. However, self-awareness as a precursor for such self-change is complicated by the fact that the post-secondary campus culture gives explicit and implicit approval for alcohol use. For example, 44\% of British Columbia (BC) undergraduates identified alcohol as an important part of university experience and 69\% agreed that they can't make it socially without drinking (Centre for Addictions Research of BC, 2008). A large proportion of students endorsed positive alcohol expectancies on campuses. While not all post-secondary students or student groups drink or drink heavily, there is ample evidence to suggest that there is a drinking culture on campuses that includes the attitudes, expectations, structures, and behaviours that promote heavy and potentially hazardous drinking in post-secondary life (Piacentini \& Banister, 2009; Dowdall, 2013). From this cultural perspective, the consequences associated with alcohol misuse, both positive and negative, are normalized by students and understood and legitimized as a typical part of the college experience. If students believe that they can resist and influence the dominant culture within which campus drinking occurs, this may create among them a sense of efficacy that could mobilize them to redefine the parameters of acceptable 
drinking and enable them to identify and modify the context that continually reinforces substance use as the norm (Reis \& Riley, 2008). It could also encourage students to develop socially accepted identities that are autonomous from existing drinking norms and challenge normative expectations and pressures related to alcohol use on campus with a view to supporting their own personal health and well-being and the health and well-being of their peers.

One aim of the Caring Campus project was to help students expand their awareness and self-efficacy with respect to drinking, with a longer goal to ultimately redefine campus culture and influence drinking behaviours. As part of the initiatives to build self-awareness and self-efficacy, we developed a Substance Use Wellness Tool. This non-pathologizing tool was intended to help students recalibrate conversations about safer consumption and its consequences and enable them to exercise self-reflection, so that students could benefit from confronting hazardous substance use and act as their own catalysts for change.

This paper describes the development and evaluation of the Substance Use Wellness Tool. As with all other initiatives described in this special issue, this project was completed as part of a three-year intervention project funded by Movember Canada. In this paper, we describe the development of the tool and its elements. Following this we report on the psychometric properties of the tool, with a view to validating its ability to identify hazardous drinking among post-secondary students.

\section{TOOL DEVELOPMENT}

Research shows that early detection of substance-related disorders enables people to receive assistance earlier in the course of the disorders (Babor et al., 2007). Examples of popular screening tools for postsecondary students include the CAGE questionnaire (Ewing, 1984), Alcohol Use Disorders Identification Test (AUDIT; Saunders, Aasland, Babor, de la Fuente, \& Grant, 1993), the CRAFFT screening test (Agley, Gassman, Jun, Nowicke, \& Samuel, 2015), Michigan Alcoholism Screening Test (MAST; Selzer, 1971), and the Drug Abuse Screening Test (DAST; Skinner, 1982). Screening tools such as these place a heavy emphasis on patterns of alcohol or other substance consumption that might indicate risky substance use behaviours, and compare the frequency of drinking/drug use against an empirically determined threshold or norm. Individuals who rank above the norm are considered at risk for hazardous drinking or drug use.

In post-secondary environments, research has indicated that the relationship between alcohol use and academic performance is complex (Ansari, Stock, \& Mills, 2013). Although a normed approach to screening has merit, a large proportion of post-secondary students exceed the heavy drinking norms and still manage to function well in their classes and obtain desirable grades (Paschall \& Freisthler, 2003). It may be that for screening tools to be useful in post-secondary campus contexts they need to be able to detect a broader range of substance use related personal and social problems that people experience (Larimer \& Cronce, 2002). For example, some tools focus only on quantity and frequency questions without identifying other dimensions of student experiences that have been associated with drinking. From a public health point of view this limits their utility. Finally, by emphasizing individual drinking or drug use patterns, these screening tools de-emphasize peer relations and shared expectations within the campus environment. Our goal was to develop a tool that focused on student substance use behaviours that would be considered emblematic of a "problem" or worthy of an "alert" as judged by the students themselves or by their colleagues. We also wanted the tool to be useful to promote self and peer reflection rather than focusing on screening or diagnostics. 
The Substance Use Wellness Tool described here was modelled after the Mental Health Continuum used by Canada's Department of National Defence. That continuum model is used widely in the military and is a centrepiece for much of the mental health promotional work done by the Mental Health Commission of Canada (Stuart et al., 2014a; Stuart et al., 2014b). The Mental Health Continuum uses a colour spectrum (ranging from green and yellow to orange and red) and avoids medical terminology in order to promote recognition of, and dialogue about, mental health problems. It employs common language about risk, normalizes and destigmatizes mental health conditions, and encourages help seeking. For example, individuals who experience emerging mild to moderate mental health problems can speak about being "yellow" or "orange." The colour spectrum has provided a new and destigmatizing language that can be used to communicate mental health risks among peers and to health professionals. Each colour along the continuum also contains a recommendation designed to promote mental wellness. A strength of the continuum is that it conveys the idea that one can move both left and right along the continuum. Through managing health and wellness better or by seeking appropriate formal or informal supports or professional help, people could move their mental health status toward the direction of "green." Over the past few decades, the public health literature has emphasized the value of recognizing a continuum of substance use, from no use to minimal use, and further to regular use and abuse (Hagman \& Cohn, 2011). Although there has been interest in identifying how young people construct and evaluate acceptable and problematic behaviours associated with substance use, these have not been, to the best of our knowledge, systematically developed as an intervention tool to address individual issues or contextual factors.

To develop the tool, we used focus groups to understand how students and peers in their social networks perceive and experience substance use in their post-secondary settings. Although focus group discussions considered substance use generally, there was a specific focus on alcohol use, given that alcohol is the most prevalent substance on campuses. During the spring of 2014, we held three focus groups with students of both genders (the first with six male students; the second with 11 female students; the third with 11 male and female students). We also held one group with three parents, with a view to understanding the family experience of student substance use. All focus groups were conducted at one university and data collection received clearance from this university's Health Research Ethics Board.

Participants were provided with a template for a substance use continuum with specific behavioural indicators according to the level of disruption in daily life, from no problems/healthy functioning (green), to mild disruption (yellow), moderate disruption (orange), and severe disruption (red). Participants discussed their observations of students who were deemed to have trouble with substance use and suggested where these students might be positioned on the coloured continuum. They were asked to focus on behavioural indicators and identified the words and ideas that they would use to understand students across the continuum. Focus group conversations were taped and transcribed verbatim. Data were coded and analyzed with a focus on describing specific thoughts, feelings, opinions, activities, experiences, and language related to substance use in the context of the campus culture. The specific domains and behavioural indicators of the continuum were revised and iteratively adjusted based on the emerging themes. An initial version of the tool was shared with the team members and a range of stakeholders on campus (including students and health and wellness providers) and further adjustments to clarity, consistency, and visual appeal were made based on their feedback. The final results were reviewed by three substance use researchers and final refinements 
were made. Continued refinements based on end-user and researcher feedback were made when the tool was disseminated in the field across three Canadian campuses.

The final Substance Use Wellness Tool consisted of 13 domains with specific behavioural indicators relating to each colour along the spectrum (see Figure 1), as follows:

1. Control describes the level of difficulty with controlling substance use. A student participant suggested that "for the moderate risk you might have regular but controlled use ... but ... for a high-risk group ... people can increase use or have difficulty with control" (S6).

2. Amount and frequency describes the amount and frequency of a student's substance use. Participants discussed the concept of "excessive use" perceived by students. They agreed that persistent use over time indicated a problem. One participant said: "Maybe it should be over a period of time because ... if it's ... St. Patrick's Day weekend, I think a lot of people are going out drinking three nights. But if you're doing that every week, ... that's ... the sign of a problem. It's not that you're doing it sometimes that you're regularly thinking three nights a week. Or being just consistently" (S2).

3. Coping describes the degree to which students use substances as a coping strategy to manage stress or negative emotions. Some participants discussed their stresses as a university student and shared peers' stories about using substances to cope with stresses. A parent also stated: "You know, the expectation if you're going to university that you're very capable and can't be struggling or you can't be homesick or sad or whatever. And then that can lead to alcohol or drugs as a way of coping with that" (P1).

4. Social-Peer pressure describes the degree to which students use substances in social situations as a response to peer pressure. Student participants discussed the campus culture as a place where drinking alcohol is a major part of socializing, and the importance of drinking to "fit in" with groups, rather than being the outsiders in the many group situations where drinking is expected. The freshman population was perceived as particularly vulnerable because they are new to university life, do not have an established identity on campus and are developing a peer group. Although peers can be an important support during the transition to university, this increase in peer pressure was also identified as a risk to develop drinking behaviours. A parent remarked that: "Kids that have a poor sense of self, they're the ones that end up getting sucked into the peer pressure and then before you know it, the alcohol itself has become an illness" (P2).

5. Pattern of use describes the social context of drinking with a particular attention to the extent to which students use substances while they are alone. The participants pointed out that drinking alone occasionally under particular conditions did not indicate a problem (for example, opening up a beer at home on a hot day after a full day of activities) but regularly drinking in isolation from others was indicative of a problem. As one male student said: "I drink to help cope with grief, depression, and suicidal thoughts and I'd rather do that alone" (S1).

6. Social-Peer use describes the degree to which peers use substances. Students whose social networks are largely composed of peers who use substances tend to view substance use as socially accepted. Where social networks are composed only or primarily of substance using peers, the 
substance use becomes an underlying norm of the social interactions, with fewer opportunities to share other patterns of social interactions on campus.

7. Motivation describes the frequency to which students use substances to get high. This domain explicates the enhancement motive of substance use that is associated with positive reinforcement such as seeking intense sensations or enjoyment. A participant described his feeling: "If I go to a party ... I'm going to go drunk 'cause parties are no fun without alcohol"' (S9).

8. Relationship describes the degree to which students' interpersonal connections are affected by substance use and whether those connections express concerns about the students' substance use. For example, a student described how comments from others was indicative of a problem and could serve as an alert: "Sort of other people's perception of it. Because I guess also some, sort of hard to reflect on yourself but if you're going to get feedback from other people about it, then that makes really a bit of a wake-up call" (S12).

9. Activity describes the degree to which students' social, occupational, and recreational activities are affected by substance use, even to the point of sacrificing other forms of non-using activities. One student described it in this way: "For example, if you were going to do something with your friends you would opt out of doing that to go to the bar for example" (S4).

10. Academic performance describes the degree to which students' academic performance is impacted by substance use. "Missing classes" is a common consequence that follows binge drinking. While the participants argued that there are infringements on performance associated with substance use that are minor, such as occasionally missing classes, "failing to meet educational goals" due to substance use would be a serious indicator of problems.

11. Physical describes the degree of impact on physical well-being experienced due to substance use. Participants shared experiences of being physically unwell after binge drinking and struggled to describe the feelings associated with this physical unwellness: "like and it's a mental thing too. I don't know it's hard, I just don't think sick is the right word, you know. Just like-Wake up in the garbage" (S5).

12. Financial describes the degree of students' financial status impacted by substance use. Participants pointed out that financial concerns are a significant indicator of being in trouble. One participant noted that: "Someone on my floor had like \$20 left in his bank account [due to alcohol use]" (S3), while others described knowing students who were left without grocery money because of their spending on substances.

13. Behavioural describes the frequency that students engage in behaviours resulting in harm to self or others due to substance use. Participants noted that engaging in risky behaviours is evident following substance use. As one participant said: "you could do just something like for the first one, you know, I get tipsy and relaxed when I drink. The second one, you know, I get drunk and do things I might not do when I'm sober and on the third one, you know, I regularly black out and do things I would never do if I was sober" (S9). 


\section{Figure 1}

The Substance Use Wellness Tool

\begin{tabular}{|c|c|c|c|c|}
\hline Control & $\begin{array}{l}\text { No or limited use of } \\
\text { substances }\end{array}$ & $\begin{array}{l}\text { Regular but controlled use of } \\
\text { substances }\end{array}$ & $\begin{array}{l}\text { Increased use of substances and } \\
\text { difficulty with control }\end{array}$ & $\begin{array}{l}\text { A persistent desire for substance and } \\
\text { unable to control use of substances }\end{array}$ \\
\hline $\begin{array}{l}\text { Amount/ } \\
\text { frequency }\end{array}$ & $\begin{array}{l}\text { No excessive use of } \\
\text { substances }\end{array}$ & $\begin{array}{l}\text { Excessive use of substances once or } \\
\text { twice a week }\end{array}$ & $\begin{array}{l}\text { Consistent excessive use of } \\
\text { substances more than two times a } \\
\text { week }\end{array}$ & $\begin{array}{l}\text { Persistently use excessive amounts of } \\
\text { substances }\end{array}$ \\
\hline Coping & $\begin{array}{l}\text { Do not use substances as a } \\
\text { coping strategy to manage } \\
\text { stresses or negative emotions }\end{array}$ & $\begin{array}{l}\text { Sometimes use substances as a } \\
\text { coping strategy to manage stresses } \\
\text { or negative emotions }\end{array}$ & $\begin{array}{l}\text { Often use substances as a coping } \\
\text { strategy to manage stresses or } \\
\text { negative emotions }\end{array}$ & $\begin{array}{l}\text { Use substances as the main coping } \\
\text { strategy to manage stresses or } \\
\text { negative emotions }\end{array}$ \\
\hline $\begin{array}{l}\text { Social- peer } \\
\text { pressure }\end{array}$ & $\begin{array}{l}\text { Never or rarely use } \\
\text { substances in social } \\
\text { situations as a response to } \\
\text { peer pressure }\end{array}$ & $\begin{array}{l}\text { Sometimes use substances in social } \\
\text { situations as a response to peer } \\
\text { pressure }\end{array}$ & $\begin{array}{l}\text { Often use substances in social } \\
\text { situations as a response to peer } \\
\text { pressure }\end{array}$ & $\begin{array}{l}\text { Almost always use substances in } \\
\text { social situations as a response to peer } \\
\text { pressure }\end{array}$ \\
\hline $\begin{array}{l}\text { Pattern of } \\
\text { use }\end{array}$ & Rarely uses substances alone & Sometimes uses substances alone & Often use substances alone & $\begin{array}{l}\text { Almost always use substances in } \\
\text { isolation }\end{array}$ \\
\hline $\begin{array}{l}\text { Social-peer } \\
\text { use }\end{array}$ & $\begin{array}{l}\text { Peers don't or only } \\
\text { occasionally use substances }\end{array}$ & Peers sometimes use substances & $\begin{array}{l}\text { Peers often focus much of their } \\
\text { activities on substance use }\end{array}$ & $\begin{array}{l}\text { Peers almost always focus their } \\
\text { activities on substance use }\end{array}$ \\
\hline Motivation & $\begin{array}{l}\text { Never use substance to get } \\
\text { high }\end{array}$ & $\begin{array}{l}\text { Sometimes use substances to get } \\
\text { high }\end{array}$ & Often use substances to get high & $\begin{array}{l}\text { Almost always use substances to get } \\
\text { high }\end{array}$ \\
\hline $\begin{array}{l}\text { Relation- } \\
\text { ship }\end{array}$ & $\begin{array}{l}\text { Connections are not affected } \\
\text { by substance use; they } \\
\text { expressed no concerns about } \\
\text { my substance use }\end{array}$ & $\begin{array}{l}\text { Connections are sometimes affected } \\
\text { by substance use; they have } \\
\text { expressed some concerns about my } \\
\text { substance use }\end{array}$ & $\begin{array}{l}\text { Connections are often affected by } \\
\text { substance use; they have expressed } \\
\text { moderate concerns about my } \\
\text { substance use }\end{array}$ & $\begin{array}{l}\text { Connections are almost always } \\
\text { affected by substance use; they have } \\
\text { expressed serious concerns about my } \\
\text { substance use }\end{array}$ \\
\hline Activity & $\begin{array}{l}\text { Social, occupational, or } \\
\text { recreational activities are not } \\
\text { sacrificed because of } \\
\text { substance use }\end{array}$ & $\begin{array}{l}\text { Social, occupational, or recreational } \\
\text { activities are sometimes replaced } \\
\text { by substance-related activities }\end{array}$ & $\begin{array}{l}\text { Social, occupational, or recreational } \\
\text { activities are often dominated by } \\
\text { substance-related activities }\end{array}$ & $\begin{array}{l}\text { Social, occupational, or recreational } \\
\text { activities are almost always } \\
\text { dominated by substance-related } \\
\text { activities }\end{array}$ \\
\hline $\begin{array}{l}\text { Academic } \\
\text { performance }\end{array}$ & $\begin{array}{l}\text { Academic performance is not } \\
\text { impacted by substance use }\end{array}$ & $\begin{array}{l}\text { Due to substance use, sometimes } \\
\text { miss classes or deadlines; } \\
\text { educational goals not in jeopardy }\end{array}$ & $\begin{array}{l}\text { Due to substance use, often miss } \\
\text { classes or deadlines; jeopardizing } \\
\text { educational goals and GPA }\end{array}$ & $\begin{array}{l}\text { Due to substance use, failing to meet } \\
\text { educational goals }\end{array}$ \\
\hline Physical & $\begin{array}{l}\text { Never felt physically unwell } \\
\text { due to substance use }\end{array}$ & $\begin{array}{l}\text { Sometimes feel physically unwell } \\
\text { due to substance use }\end{array}$ & $\begin{array}{l}\text { Often feel physically unwell due to } \\
\text { substance use }\end{array}$ & $\begin{array}{l}\text { Recurrent substance use results in } \\
\text { poor physical well-being }\end{array}$ \\
\hline Financial & $\begin{array}{l}\text { Finances are not impacted by } \\
\text { substance use }\end{array}$ & $\begin{array}{l}\text { Finances are occasionally impacted } \\
\text { by substance use }\end{array}$ & $\begin{array}{l}\text { Finances are often impacted by } \\
\text { substance use }\end{array}$ & $\begin{array}{l}\text { Have significant financial troubles } \\
\text { (spend most money on substances) }\end{array}$ \\
\hline \multirow[t]{2}{*}{ Behavioural } & $\begin{array}{l}\text { Never engage in behaviours } \\
\text { resulting in harm to self or } \\
\text { others due to substance use }\end{array}$ & $\begin{array}{l}\text { Sometimes engage in behaviours } \\
\text { resulting in harm to self or others } \\
\text { due to substance use }\end{array}$ & $\begin{array}{l}\text { Often engage in behaviours } \\
\text { resulting in harm to self or others } \\
\text { due to substance use }\end{array}$ & $\begin{array}{l}\text { Almost always engage in behaviours } \\
\text { resulting in harm to self or others due } \\
\text { to substance use }\end{array}$ \\
\hline & & $\begin{array}{l}\text { CAUTION } \\
\text { Recognize your substance- } \\
\text { related issues, seek support }\end{array}$ & $\begin{array}{c}\text { ALERT } \\
\text { Talk to someone, seek profes- } \\
\text { sional help, make self-care a } \\
\text { priority. Don't withdraw. }\end{array}$ & $\begin{array}{c}\text { ALARM } \\
\text { Seek professional help. }\end{array}$ \\
\hline
\end{tabular}

Note: To download a colour version of the tool, go to http://caringcampus.ca/resources/ 


\section{PSYCHOMETRIC TESTING}

\section{Methods}

We conducted campus-wide surveys in three Canadian universities in two provinces to test the factor structure, internal consistency, and construct (convergent) validity of the tool. Data were collected during the spring of 2015 and winter of 2016. Surveys received appropriate ethics clearance from each university.

In two universities, an email with an online survey link was sent to all undergraduate students inviting them to participate in a survey. In the third university, the Research Participation System, run by the Psychology Department, was used to recruit students. This system is open to all undergraduate psychology students and allows them to participate in research projects for class credit.

Participants provided informed consent and then indicated which item best reflected their situation with respect to their use of alcohol or other substances over the past four weeks, across each of the 13 domains of the Substance Use Wellness Tool. Items were scored from 1 (reflecting "green") to 4 (reflecting "red").

In addition to the Substance Use Wellness Tool, we used the 10-item Alcohol Use Disorders Identification Test (AUDIT; Saunders et al., 1993) as the gold standard against which to test construct (convergent) validity. The AUDIT is a reliable and valid self-administered instrument to identify at-risk drinkers and alcoholdependent individuals (Daeppen, Yersin, Landry, Pécoud, \& Decrey, 2000; Allen, Litten, Fertig, \& Babor, 1997; Kokotailo et al., 2004). The AUDIT contains 10 items with five response alternatives for the first eight items. The last two items have only three response alternatives. Responses were scored from low (0) to high ( 2 or 4 points, depending on the item) and the total points were added to determine the AUDIT level of alcohol use. Higher scores reflect more problematic drinking.

To assess the factor structure of the scale, we used a two-step internal replication analysis described by Osborne and Fitzpatrick (2012). First, the sample was split in half randomly. Each sub-sample was then analyzed separately using specific extraction guidelines. In the exploratory analysis, we allowed multiple factors to emerge; however in this paper, for ease of reporting, we show loadings on the first two factors. In the confirmatory analysis, we constrained the analysis to one factor. Otherwise, our analyses were identical. Because the items were ordinally scaled, we use a polychoric correlation matrix as input into the principal components analysis. The factor structure emerged clearly without rotation. We compared the factor loadings from each sample and calculated the squared differences. Osborne and Fitzpatrick suggest that squared differences of .04 or greater indicate volatile loadings and were items that may be candidates for omission. We also calculated the reliability of the scale in each sample using Cronbach's alpha. Finally, because the AUDIT and the Substance Use Wellness tool were not normally distributed, Spearman's rank order correlation was used to assess convergent validity of the new tool against the well-established AUDIT.

\section{RESULTS}

A total of 4,206 students participated in this study. Table 1 shows the descriptive results, AUDIT scores, and scores on the Substance Use Wellness Tool from each university separately and all universities combined. The sample was predominantly female at every university, with the largest proportion (83.2\%) coming from University C. A small proportion ( $0.9 \%$ overall) identified their gender as "other." These participants were 
Table 1

Descriptive Results, AUDIT scores, and Scores on the Substance Use Wellness Tool

\begin{tabular}{|c|c|c|c|c|}
\hline & $\begin{array}{l}\text { University A } \\
(\mathrm{N}=554)\end{array}$ & $\begin{array}{l}\text { University B } \\
(\mathrm{N}=3,188)\end{array}$ & $\begin{array}{l}\text { University } C \\
(\mathrm{~N}=464)\end{array}$ & $\begin{array}{l}\text { Total (All } \\
\text { Combined) } \\
(\mathrm{N}=4,206)\end{array}$ \\
\hline \multicolumn{5}{|l|}{ Gender } \\
\hline Male & $177(32.1 \%)$ & $953(29.9 \%)$ & $78(16.8 \%)$ & $1,208(28.8 \%)$ \\
\hline Female & $371(67.2 \%)$ & $2195(69.0 \%)$ & $385(83.2 \%)$ & $2,951(70.3 \%)$ \\
\hline Other & $4(0.7 \%)$ & $35(1.1 \%)$ & - & $39(0.9 \%)$ \\
\hline \multicolumn{5}{|l|}{ Year } \\
\hline 1 st & $119(21.5 \%)$ & $695(21.8 \%)$ & $138(29.7 \%)$ & $952(22.7 \%)$ \\
\hline 2 nd & $136(24.5 \%)$ & $610(19.1 \%)$ & $104(22.4 \%)$ & $850(20.2 \%)$ \\
\hline $3 \mathrm{rd}$ & $153(27.6 \%)$ & $701(22.0 \%)$ & $95(20.5 \%)$ & $949(22.6 \%)$ \\
\hline 4 th & $100(18.1 \%)$ & $652(20.5 \%)$ & $76(16.4 \%)$ & $828(19.7 \%)$ \\
\hline 5 th and up & $46(8.3 \%)$ & $526(16.5 \%)$ & $51(11.0 \%)$ & $623(14.8 \%)$ \\
\hline \multicolumn{5}{|l|}{ AUDIT } \\
\hline Zone I Low risk & $337(60.8 \%)$ & $2490(78.1 \%)$ & $362(78 \%)$ & $3,189(75.8 \%)$ \\
\hline Zone II Risky & $171(31.9 \%)$ & $573(18.0 \%)$ & $78(16.8 \%)$ & $822(19.5 \%)$ \\
\hline Zone III High, counselling & $26(4.7 \%)$ & $69(2.2 \%)$ & $15(3.2 \%)$ & $110(2.6 \%)$ \\
\hline Zone IV High, harm & $20(3.6 \%)$ & $56(1.8 \%)$ & $9(1.9 \%)$ & $85(2.0 \%)$ \\
\hline \multicolumn{5}{|c|}{ Substance Use Wellness Tool: mean item score (SD) } \\
\hline Overall disruption level & $1.31(.56)$ & $1.21(.52)$ & $1.16(.43)$ & $1.22(.52)$ \\
\hline 1. Control & $1.63(.60)$ & $1.32(.55)$ & $1.26(.48)$ & $1.35(.56)$ \\
\hline 2. Amount/frequency & $1.50(.66)$ & $1.23(.55)$ & $1.19(.48)$ & $1.26(.56)$ \\
\hline 3. Coping & $1.34(.58)$ & $1.30(.57)$ & $1.26(.54)$ & $1.30(.56)$ \\
\hline 4. Social, peer pressure & $1.44(.62)$ & $1.22(.49)$ & $1.19(.45)$ & $1.24(.51)$ \\
\hline 5. Pattern of use & $1.27(.58)$ & $1.25(.58)$ & $1.22(.56)$ & $1.25(.58)$ \\
\hline 6. Social, peer use & $2.50(.73)$ & $1.78(.74)$ & $1.79(.78)$ & $1.84(.76)$ \\
\hline 7. Motivation & $1.51(.70)$ & $1.31(.64)$ & $1.28(.59)$ & $1.33(.65)$ \\
\hline 8. Relationship & $1.15(.40)$ & $1.09(.34)$ & $1.09(.33)$ & $1.10(.35)$ \\
\hline 9. Activity & $1.21(.47)$ & $1.12(.39)$ & $1.11(.37)$ & $1.13(.40)$ \\
\hline 10. Academic performance & $1.18(.41)$ & $1.10(.34)$ & $1.11(.37)$ & $1.11(.35)$ \\
\hline 11. Physical & $1.58(.62)$ & $1.30(.50)$ & $1.33(.54)$ & $1.36(.53)$ \\
\hline 12. Financial & $1.24(.49)$ & $1.89(.46)$ & $1.16(.43)$ & $1.19(.46)$ \\
\hline 13. Behavioural & $1.19(.45)$ & $1.09(.31)$ & $1.09(.34)$ & $1.10(.34)$ \\
\hline
\end{tabular}


Table 2

Factor Loadings from the Replicability Analysis with Randomly Selected Samples

\begin{tabular}{lllll}
\hline \multirow{2}{*}{ Item } & $\begin{array}{l}\text { Sample 1 } \\
(\mathrm{N}=2063)\end{array}$ & & $\begin{array}{l}\text { Sample 2 } \\
(\mathrm{N}=2143)\end{array}$ & \multirow{2}{*}{ Squared Difference } \\
\cline { 2 - 4 } & Factor 1 & Factor 2 & Factor 1 & \\
\hline Control & .88 & -.16 & .89 & .0001 \\
Amount & .87 & -.12 & .87 & 0 \\
Coping & .80 & -.22 & .79 & .0001 \\
Peer & .54 & .44 & .59 & .0025 \\
Pattern & .56 & -.25 & .54 & .0004 \\
Peer Use & .57 & .34 & .57 & 0 \\
Motivation & .71 & -.10 & .73 & .0004 \\
Relationships & .81 & -.07 & .80 & .0001 \\
Activity & .83 & .01 & .81 & .0004 \\
Academic & .81 & -.04 & .83 & .0004 \\
Physical & .80 & .22 & .78 & .0004 \\
Financial & .80 & .09 & .77 & .0009 \\
Behavioral & .80 & .06 & .74 & .0036 \\
Eigenvalue & & & & \\
Variance Explained & 9.53 & 0.54 & 7.39 & \\
\hline
\end{tabular}

Table 3

Spearman's Rank Order Correlation of Aggregated Substance Use Wellness Score with the 10-item Aggregated AUDIT Score

\begin{tabular}{llll}
\hline Item & $\mathrm{N}$ & Correlation & P-value \\
\hline Gender & & & \\
Male & 1208 & .69 & $<.001$ \\
Female & 2951 & .71 & $<.001$ \\
Year & & & \\
1 & 952 & .71 & $<.001$ \\
2 & 850 & .71 & $<.001$ \\
3 & 949 & .69 & $<.001$ \\
4 & 828 & .72 & $<.001$ \\
$5+$ & 340 & .66 & $<.001$ \\
Site: & & & $<.001$ \\
University A & 3188 & .68 & $<.001$ \\
University B & 554 & .75 & $<.001$ \\
University C & 464 & .68 & $<.001$ \\
& & & \\
Overall & 4206 & .71 & \\
\hline
\end{tabular}


omitted from further gender-based analyses. The bulk of participants were undergraduate students and fairly evenly distributed across years one to four. The mean aggregated AUDIT score was 4.9 (SD = 5.1; median =4). The majority of students at each university ( $76 \%$ overall) were scored as "low risk" on the AUDIT, while $24 \%$ were rated as risky or higher, with almost $5 \%$ meeting criteria for significant harm. With respect to the item scores for the Substance Use Wellness Tool, the majority of students scored below the mid-point for any single item, with the exception of students at University A, who scored above the mid-point for peer pressure use, on average, making this the highest scoring item overall. The mean aggregated score was 16.5 $(\mathrm{SD}=4.2$; median 14.5).

Table 2 shows the factor structure of the Substance Use Wellness Tool. In both the exploratory and confirmatory analyses, a single large eigenvalue emerged (7.5 and 7.4 respectively) indicating a one-factor structure. The second factor in the exploratory analysis had an eigenvalue of .54, which accounted for $6 \%$ of the variance, and was demarcated by a single significant item related to peer pressure, which had also loaded on the first factor. Factor loadings were strong (all above .50) and similar in both samples for the first factor. Further, the squared differences in the factor loadings were small across random sub-samples, indicating that all items should be retained. Cronbach's alphas were excellent: .86 at University A; .87 at University B; .86 at University $\mathrm{C}$, and .87 overall.

Table 3 shows the Spearman's rank order correlations between the aggregated Substance Use Wellness Tool measure and the aggregated AUDIT score by sub-groups based on gender, year of study, site, and for the entire sample. Correlations ranged from .68 to 71 and were robust to subgroup membership. The coefficient of determination $\left(\mathrm{r}^{2}\right)$ indicated that about half of the variation in the AUDIT score was predicted from the Substance Use Wellness Tool score.

\section{DISCUSSION}

This paper describes the development and initial validation of the Substance Use Wellness Tool (see Figure 1) for hazardous drinking among post-secondary students. The tool is intended to be a self- and peer-assessment guide that post-secondary students can use to reflect on, monitor, and alter patterns of substance use. The Substance Use Wellness Tool uses a four-colour continuum (ranging from green and yellow to orange and red) to reflect the extent to which patterns of alcohol use are problematic and interfere with daily functioning. Given the high prevalence of heavy drinking and other substance misuse on campus (Kwan, Faulkner, Arbiur-Nicitopoulos, \& Cairney, 2013), it incorporates behavioural cues to identify patters of misuse, which were grounded in students' perceptions of what behaviours were problematic within the context of campus life.

Exploratory and confirmatory factor analysis showed that the tool loaded strongly on a single dimension and that all 13 domains that are assessed within the tool were important, as they loaded above the .5 threshold for salient factor loadings. Cronbach's alpha indicated the tool was highly internally consistent across subsamples. Convergent validity with the 10-item AUDIT was also good, with strong correlations, both overall and within subgroups defined by gender, year of study, and university site. Overall, the results provide a strong preliminary validation of the tool, and suggest it may be useful in alcohol programs in post-secondary settings. 
Despite the strong results in the current study, further validation of the tool is warranted. Replication of the factor structure in a novel sample of post-secondary students would help to assure its internal structure. Also, although we assessed convergent validity of the tool against a standard alcohol use tool, it would be important to further evaluate both convergent and divergent validity and expand the analysis to include other substances. Further, although our sample was large, it was not sufficient to fully evaluate the potential moderating effect of variables such as cultural background or ethnicity. The sensitivity of the tool to changes in alcohol related behaviour over time, or to systemic changes within institutions remains unstudied at present. Also, although alcohol is the most prevalent substance on campuses, the tool may be relevant to other substances, as the domains were developed with student input to be generic to any substance. It may be, however, that similar future studies could shed light on if and how there are particular indicators associated with particular substances that could be captured in such a tool. This possibility remains to be studied.

The tool was designed to be feasible to implement across different post-secondary environments and is available for widespread dissemination and branding to fit the specific campus cultural context. We have disseminated the tool in a variety of ways within the universities that participated in the Caring Campus project. Each site tailored and branded the tool to their specific campus context. For example, with respect to strategic distribution, we created a leaflet containing the tool and a description of its purpose that was distributed to students in campus kits and provided to student wellness services to be incorporated into drinking awareness activities. We also disseminated the tool more widely within various mental health organizations' workshops on campus. University stakeholders included the tool in various places, such as student residences, orientation leadership workshops, student workshops, and peer support training. The tool was also used in educational sessions to promote dialogue about how substance use may be expressed within particular student groups. For example, the tool has been presented in health and wellness workshops with varsity student athletes who discussed how alcohol use was expressed and sustained in their particular contexts and the meaning of this use. While the tool provides an excellent structure for health promotion activities in post-secondary environments, future research is required to help us understand whether the tool can truly be a part of a strategy that helps students move from awareness to action, and to modify risky drinking and drug use behaviours.

\section{REFERENCES}

Allen, J. P., Litten, R. Z., Fertig, J. B., \& Babor, T. (1997). A review of research on the Alcohol Use Disorders Identification Test (ADDIT). Alcoholism: Clinical and Experimental Research, 4, 613-619.

Ansari, W. E., Stock, C., \& Mills, C. (2013). Is alchohol consumption associated with poor academic achievement in universty students? International Journal of Preventive Medicine, 1(1), 1175-1188.

Agley, J., Gassman, R. A., Jun, M., Nowicke, C., \& Samuel, S. (2015). Statewide administration of the CRAFFT screening tool: Highlighting the spectrum of substance use. Substance Use \& Misuse, 50(13), 1668-1677.

Babor, T. F., McRee, B. G., Kassebaum, P. A., Gromaldi, P. L., Ahmed, K., \& Bray, J. (2007). Screening, brief intervention, and referral to treatment (SBIRT): Toward a public health approach to the management of substance abuse. Substance Abuse, 28(3), 7-30.

Centre for Addictions Research of BC. (2008). Alcohol on campus: Programs and policies. Retrieved from https:// campusmentalhealth.ca/wp-content/uploads/2014/06/AlcoholOnCampus.pdf 
Daeppen, J.-B., Yersin, B., Landry, U., Pécoud, A., \& Decrey, H. (2000). Reliability and Validity of the Alcohol Use Disorders Identification Test (AUDIT) imbedded within a general health risk screening questionnaire: Results of a survey in 332 primary care patients. Alcoholism: Clinical and Experimental Research, 24, 659-665.

Das, J., Salam, R., Arshad, A., Finkelstein, Y., \& Bhutta, Z. (2016). Interventions for adolescent substance abuse: An overview of systematic reviews. Journal of Adolescent Health, 59, S61-S75.

Dowdall, G. W. (2013). College drinking: Reframing a social problem/changing the culture. Sterling, Virginia: Stylus Publishing, LLC.

Ewing, J. A. (1984). Detecting alcoholism: The CAGE questionnaire. Journal of the American Medical Association, 252(14), 1905-1907.

Hagman, B. T., \& Cohn, A. M. (2011). Toward DSM-V: Mapping the alchohol use disorder continuum in college students. Drug and Alcohol Dependence, 118(2), 202-208.

Johnston, L. D., O’Malley, P. M., Bachman, J. G., Schulenberg, J. E., \& Miech, R. A. (2016). Monitoring the future national survey results on drug use, 1975-2015: Volumn II, college students and adults ages 19-55. The National Institute on Drug Abuse at The National Institutes of Health, Institute for Social Research. Ann Arbor: The University of Michigan.

Kokotailo, P. K., Egan, J., Gangnon, R., Brown, D., Mundt, M., \& Fleming, M. (2004). Validity of the Alcohol Use Disorders Identification Test in college students. Alcoholism: Clinical and Experimental Research, 28, 914-920.

Kwan, M., Faulkner, G., Arbiur-Nicitopoulos, K., \& Cairney, J. (2013). Prevalence of health risk behaviours among Canadian post-secondary students: Descriptive results from the National College Health Assessment. BMC Public Health, 13, 548.

Larimer, M. E., \& Cronce, J. M. (2002). Identification, prevention, and treatment: A review of individual-focused strategies to reduce problematic alcohol consumption by college students. Journal of Studies on Alcohol, Suppl. $14,148-163$.

Misch, D. (2010). Changing the culture of alcohol abuse on campus: Lessons learned from secondhand smoke. Journal of American College Health, 59(3), 232-234.

Osborne, J., \& Fitzpatrick, D. (2012). Replication analysis in exploratory factor analysis: What it is and why it makes your analysis better. Practical Assessment Research \& Evaluation, 17(15), 1-8.

Paschall, M. J., \& Freisthler, B. (2003). Does heavy drinking affect academic performance in college? Findings from a prospective study of high achievers. Journal of Studies on Alcohol, 64(4), 515-519.

Piacentini, M. G., \& Banister, E. N. (2009). Managing anti-consumption in an excessive drinking culture. Journal of Business Research, 62, 279-288.

Reis, J., \& Riley, W. (2008). First-year students' views on changing their campus alcohol culture. NASPA Journal, 45(2), 192-209.

Saunders, J. B., Aasland, O. G., Babor, T. F., de la Fuente, J. R., \& Grant, M. (1993). Development of the Alcohol Use Disorders Identification Test (AUDIT): WHO collaborative project on early detection of persons with harmful alcohol consumption - II. Addition, 88, 791-804.

Selzer, M. (1971). The Michigan Alcoholism Screening Test: The quest for a new diagnostic instrument. American Journal of Psychiatry, 127, 1653-1658.

Skinner, H. A. (1982). The Drug Abuse Screening Test. Additive Behaviors, 7(4), 363-371.

Sobell, M. B., \& Sobell, L. C. (2005). Guided self-change model of treatment for substance use disorders. Journal of Cognitive Psychotherpay: An Internaltioanl Quarterly, 19(3), 199-210.

Stuart, H., Chen, S.-P., Christie, R., Dobson, K., Kirsh, B., Knnak, S., . . Szeto, A. (2014a). Opining minds in Canada: Background and rationale. Canadian Journal of Psychiatry, 58, S8-S12.

Stuart, H., Chen, S.-P., Christie, R., Dobson, K., Kirsh, B., Knnak, S., . . Szeto, A. (2014b). Opining minds in Canada: Targeting change. Canadian Journal of Psychiatry, 59, S13-S18. 